\title{
Effect of Educational Program regarding Evidence Based Practice on Beliefs and Implementation among Clinical Instructors.
}

\section{Essam Ahmed Abdelhakam1, Mona Mostafa Shazly2, Safaa Mohamed Abdelrahman3, Sahar Ahmed Abood 4}

\author{
${ }^{1}$ Assist. lecturer, Nursing Administration, faculty of nursing ,Minia University \\ ${ }^{2}$ Professor, Nursing Administration, faculty of nursing, Ain Shams University, Egypt. \\ ${ }^{3,4}$ Professor, Nursing Administration, faculty of nursing, Minia University, Egypt
}

\begin{abstract}
Background: Evidence-based practice (EBP) is a systematic approach to improving the quality of nursing practice.Aim: The current study aims to investigate the effect of educational program regarding evidence based practice on beliefs and implementation among Clinical instructors. Design: A quasi-experimental research was utilized. Setting: The study was carried out at Faculty of Nursing, Minia University. Subjects: convenient sample of all available (78) clinical instructors who were working in a six Departments in Faculty of Nursing at Minia University at the time of conducting the study. Tools: Two tools were used; the Evidence-Based Practice Beliefs (EBPB) Scale, and the EBP implementation (EBPI) scale. Results: showed that total mean scores of clinical instructors' evidence-based practice implementation was increased post program than pre-program and follow up session was increased than pre and post program and total mean scores of clinical instructors' evidence-based practice beliefs was increased post program than pre-program and follow up session was increased than pre and post program with highly statistically significance differences which $P$ - value .0001 respectively. Conclusion: Findings of the research demonstrated that education can affect the clinical instructor's belief and implementation to use EBP. Recommendations: Repetition of the educational program in other nursing Faculties needs to be done on the use and implementation of EBP.
\end{abstract}

Key words: Evidence-based practice, Beliefs, Implementation, Clinical Instructors.

\section{Introduction}

Evidence-based practice (EBP) has become the goldstandard of care in the nursing discipline today. Healthcare and educational institutions need to shift focus on EBP. Subsequently, health professionals are expected to possess the competency in the implementation of EBP to meet the demands of the health care system in this twenty first century. To fulfill this need, numerous academic strategies in the introduction of EBP to undergraduate nursing baccalaureate education have been implemented to prepare future nurses (1).

Evidence-based practice in healthcare is a decisionmaking approach for patient care that integrates the best scientific evidence with the clinician's expertise and the patient's preference for care (2).

Nursing faculty's primary goal is to prepare future nurses for clinical practice with competencies to provide safe and quality patient-centered care. Healthcare requires timely information for effective decision-making, and requires the integration of health information-seeking skills throughout nursing education curricula to effectively promote evidencebased practice (3).

Nurse educators or clinical instructors play a key role in creation of opportunities for implementing EBP and in facilitating the implementation process. The question now is how to foster implementation of EBP. The most important factor that is likely to help nurses and nurse educators to adopt $\mathrm{EBP}$ is the provision of adequate training in $\operatorname{EBP}(4)$.

Nurses need to be competent and confident embracing evidence-based practice as a standard of care, and faculty must seamlessly integrate sufficient skills to navigate electronic databases, comprehend and analyze research, and make decisions based on evidence throughout the various program curricula for nursing practice (5).

Cobus-Kuo and Waller, (2016) concurred with Pierce and reported that the evidence-based practice process requires information literacy skills, which are complex research skills developed over time and with repetitive practice. Nurses need to be knowledgeable and confident in making clinical decisions based on reliable and current evidence, and both competencies should be integrated throughout nursing curricula for students to value and appreciate the importance of evidence-based practice (6)

\section{Significance of the Study}

EBP is one of the main professional competencies for health care professionals and a priority for nursing and medical education programs as well. Nursing educators have responsibility to teach the future nurses, and an opportunity to promote positive patient outcomes. Nursing educators are in charge for training the future nurses, so their participation in integrating the EBP into clinical education will improve healthcare outcomes (7). They must involve themselves in clinical issues and approximate clinical, educational, and research activities through teaching EBP to students and nurses. This requires nursing educators to have sufficient knowledge and skills in EBP before involvement in this sophisticated practice (8).

Despite the significant amount of literature regarding the benefits of EBP and nurse' positive attitudes toward it, there are many barriers to implementing EBP, and the process of implementing EBP is slow. Lack of time to search for evidence, lack of understanding and interpreting skills for research findings, inadequate access to information technology, limited information technology (IT) skills, lack of autonomy to change practice, and lack of information searching skills are examples of these barriers. Within many healthcare professions such as dentistry, physical therapy, nursing, and medicine, it is estimated that it takes approximately 17 years on average to translate research findings into clinical practice to improve patients' outcomes (9). 


\section{Aim of the study}

The aim of this study was to investigate the effect of educational program regarding evidence based practice on beliefs and implementation among Clinical instructors

\section{Research Hypothesis}

1. Clinical Instructor' beliefs toward EBP will be positive after the educational program than before.

2. Clinical Instructor' implementation of EBP will be higher after the educational program than before.

\section{Subjects and methods}

Research design:

Quasi-experimental design was utilized in this study.

\section{Setting:}

Faculty of Nursing at Minia University. The study was conducted at Faculty of nursing, Minia University that was established in (1995) by Presidential Decree number (184) as Higher Institute of Nursing which was affiliated the Faculty of Medicine then issued Presidential Decree number (200) of year(2000) to turn it to a Faculty of Nursing. The study started in the academic year 1997/1998.

\section{Subjects}

A convenience sample of all available (78) clinical instructors who were working in a six Departments in Faculty of Nursing at Minia University at the time of conducting the study and willing to participate in the study was included. Distribution of sample as follows Nursing Administration Department 13, Woman Health and Obstetrics Nursing Department 11, Pediatric Nursing Department 9, MedicalSurgical Nursing Department 26, Community Health Nursing 9 and Psychiatric Health Nursing 10

\section{Tools of data collection:}

Two tools were used in this study as follows: -

First Tool: "The Evidence-Based Practice Beliefs (EBPB) Scale" it includes two parts:

$\underline{1^{\text {st }}}$ part: - the socio- demographic characteristics of the studied subjects such as (age, gender, Educational qualification, years of experience, Department and marital status).

$2^{\text {nd }}$ part: - The Evidence-Based Practice Beliefs (EBPB) Scale. The scale was developed by Melynk and Fineout-Overholt, (2008) (10). It consists of 16 item. The EBPB Scale is five point Likert-type scale designed to measure beliefs about EBP. Responses ranged from $1=$ strongly disagree to $5=$ strongly agree and included two reverse scored items $11 \& 13$. The 16 items on the scale were summed with a possible score ranging from 16 to 80 .

\section{Scoring System:}

The range of scores for the EBPB is 16 to 80 . Interpretation markers are 16, 32, 48, 64 and 80; therefore, scores below a 64 indicate that there is less than agreement with their knowledge of, confidence in and belief in their ability to implement EBP. But when scores were above 48 (neither agree or disagree) (but less than 64) indicate that there is not full commitment at this point to EBP while scores were lower than 48 indicate there is no commitment to EBP. Overall, the closer to 64, the more commitment/belief in EBP. Mean scores $>64$ indicate a firm belief in and confidence about implementing EBP.

\section{Second Tool: "The Evidence-Based Practice} Implementation (EBPI) Scale ":

The EBPI scale is an 18-items scored on five point Likert scale based on how many times the participant utilized EBP during the previous 8 weeks. The respondents performed the item in question ( $1=0$ times to $5 \leq /=8$ times).

\section{Scoring System:}

The range of scores for EBPI is 18 to 90 . To interpret the EBPI scores, a response of $0-17$ indicates that in the past 8 weeks respondents have implemented EBP less than 1 time. An overall mean score of 18 - 35 would indicate respondents have implemented EBP between 1-3 but less than 4 times within the past 8 weeks. A score between $36-53$ would indicate that respondents have implemented EBP between 4-5 but less than 6 times within the past 8 weeks. A score of $54-$ 71 would indicate that respondents had implemented EBP between 6-7 but less than 8 times and a score of 72 would indicate respondents had implemented EBP 8 times or more within the past 8 weeks.

\section{Validity and reliability}

The validity were revised and validated by a panel of five experts in Nursing Administration field. The reliability analysis of the study tools was done using alpha coefficient to measure the stability of its internal consistency; it was (0.962)for the Evidence-Based Practice Beliefs (EBPB) Scale, while the test value for the EBP implementation (EBPI) scale was (0.977). Thus indicate High reliability for both tools.

Pilot Study

A pilot study was carried out on $10 \%$ of participants (8 clinical instructors) working in the Faculty of Nursing ,Minia University who fulfilled the inclusion criteria to test the feasibility, objectivity, applicability of the study tools, accessibility of study participants and to estimate the needed time to fill the data collection. Based on the results of the pilot study, no refinement/ modifications were done for data collection instruments; Clinical Instructors who shared in the pilot study were included in the actual study sample.

\section{Procedure}

An official permission was obtained from the Dean of Faculty of Nursing, Minia University where the study was carried out. The study was conducted in three phases: Assessment and planning phase, implementation phase, as well as evaluation phase.

\section{A)Assessment and planning phase:}

- The purpose of the study was simply explained to the clinical instructors who agree to participate in the study prior to any data collection.

- Individual oral consent was obtained from each participant after explaining the nature and benefits of the study.

- The researcher maintained anonymity and confidentiality of participant.

- Participants were allowed to choose to participate or not in the study, and given the right to withdraw at any time from the study without giving reasons.

- The study tools were filled in and completed by the participants on 3 stages (pre, post \& follow up implementation of program). 
- Data collection (pretest) was started and completed within 2 months / 2 days per week, starting from May 2018 to June 2018.

\section{B)Implementation phase:}

- The program content and its objectives were developed by the researcher in the form of 4 sessions.

- Each session of the educational program had taken about 2 hours for 2 days per week for each group of clinical instructor to develop their beliefs toward using EBP . These sessions were conducted for each Department.

- The sessions were conducted in Faculty of Nursing, Minia University.

- Implementation of educational program lasted over a period of (6) months, starting from September 2018 to February 2019 for all participants under the study.

- At the beginning of the first session, an orientation of the evidence based practice educational program and its purpose took place. The importance and benefit of the program were explained to all the participants under the study.

- Educational program was divided into four sessions:

$\checkmark$ Session 1: Introductory session, definition and importance of evidence-based practice.

$\checkmark$ Session 2: sources and steps of evidence-based Practice.

$\checkmark$ Session 3: models, Barriers and facilitators of evidence-based practice.

$\checkmark$ Session 4: Giving example about the application of evidence-based practice in nursing and Immediate post-test by using tool I part 2 and tool II .

$\checkmark \quad$ The booklet was handed for every participant.

\section{C)Evaluation and follow up Phase:}

The evaluation phase was done to determine the effect of educational program on clinical instructor' beliefs toward using EBP through filling in the same tools again after implementation of the program. The collection of data was done immediately after the application of the EBP program. Then follow up was done after three months of program implementation by using the same tools.

\section{Ethical considerations}

Official permission to conduct the study was obtained from Faculty Ethical Committee of Research, Dean of the Faculty of Nursing at Minia University. Oral consent was obtained from each clinical instructor after explanation of the nature and purpose of the study. Each clinical instructor was free to either participate or not in this study and had the right to withdraw from the study at any time without any rational; also, clinical instructors were informed that data will not be included in any further researches without another new consent. Confidentiality and anonymity of each subject was assured through coding of all data.

\section{Statistical design}

The collected data were tabulated \& statistically analyzed using software program and statistical package for social science (IBM SPSS 25.0) to evaluate clinical instructors involved in the study. The statistically analysis included percentage (\%), mean, stander deviation (SD). Fisher's exact test used to detect differences between more than two variables and the sample size is small. Quantitative continuous data were compared by using Friedman test in case of comparisons between the mean scores of the three times of studied group. Graphs were done for data visualization using Microsoft Excel. Correlation test and $\mathrm{P}$ - value of $\leq 0.05$ indicates a significant result while, $P$ value of $>0.05$ indicates a non-significant result.

\section{Results}

Table (1): Percentage distribution of socio-demographic characteristics of clinical instructors in Faculty of Nursing, Minia University in the study sample $(n=78)$

\begin{tabular}{|c|c|c|}
\hline Socio -demographic characteristics & No. & $\%$ \\
\hline \multicolumn{3}{|l|}{ Age/year } \\
\hline $23-28$ & 25 & 32.1 \\
\hline $29-34$ & 39 & $\mathbf{5 0 . 0}$ \\
\hline $35-40$ & 14 & 17.9 \\
\hline Mean \pm SD & \multicolumn{2}{|c|}{$30.4 \pm 3.9$ years } \\
\hline \multicolumn{3}{|l|}{ Gender } \\
\hline Male & 12 & 15.4 \\
\hline Female & 66 & 84.6 \\
\hline \multicolumn{3}{|l|}{ Marital status } \\
\hline Single & 20 & 25.6 \\
\hline Married & 58 & 74.4 \\
\hline \multicolumn{3}{|l|}{ Educational qualification } \\
\hline Bachelor degree of Nursing Science & 24 & 30.8 \\
\hline Master degree of Nursing Science & 54 & 69.2 \\
\hline \multicolumn{3}{|l|}{ Years of experience } \\
\hline $1-5$ & 31 & 39.7 \\
\hline $6-10$ & 25 & 32.1 \\
\hline $11-15$ & 22 & 28.2 \\
\hline Mean \pm SD & \multicolumn{2}{|c|}{$7.4 \pm 4.1$ years } \\
\hline \multicolumn{3}{|l|}{ Department } \\
\hline Nursing Administration & 13 & 16.7 \\
\hline Medical- Surgical Nursing & 26 & 33.3 \\
\hline Pediatric Nursing & 9 & 11.5 \\
\hline Community Health Nursing & 9 & 11.5 \\
\hline Psychiatric Health Nursing & 10 & 12.8 \\
\hline Woman Health and Obstetrics Nursing & 11 & 14.2 \\
\hline
\end{tabular}


Minia Scientific Nursing Journal (Print) (ISSN 2537-012X) Vol. (7) No. (1) June 2020

Table (1): reveals that, $50.0 \%$ of clinical instructors aged between $29-34$ years with mean aged $30.4 \pm 3.9$ years, $84.6 \%$ of them were females, $74.4 \%$ of them married and $69.2 \%$ of them had master degree. Regarding years of experience $39.7 \%$ of clinical instructors their experience ranged between 1- 5 years and 33.3\% of sample was in Medical Surgical department.

Table (2): Relations between clinical instructors' evidence-based practice beliefs in pre, post and follow-up program $(\mathrm{n}=78)$.

\begin{tabular}{|c|c|c|c|c|c|c|c|c|c|c|c|c|c|c|c|}
\hline \multirow{3}{*}{ Statement } & \multicolumn{5}{|c|}{ Pre } & \multicolumn{5}{|c|}{ Post } & \multicolumn{5}{|c|}{ Follow up } \\
\hline & SD & D & $\mathbf{N}$ & $\mathbf{A}$ & $\mathbf{S A}$ & SD & D & $\mathbf{N}$ & $\mathbf{A}$ & $\mathbf{S A}$ & SD & D & $\mathbf{N}$ & $\mathbf{A}$ & $\mathbf{S A}$ \\
\hline & $\%$ & $\%$ & $\%$ & $\%$ & $\%$ & $\%$ & $\%$ & $\%$ & $\%$ & $\%$ & $\%$ & $\%$ & $\%$ & $\%$ & $\%$ \\
\hline $\begin{array}{l}\text { EBP results in the best } \\
\text { clinical care for patients. }\end{array}$ & 0.0 & 7.7 & 15.4 & 47.4 & 29.5 & .0 & .0 & 1.3 & 32.1 & 66.7 & .0 & .0 & .0 & 1.3 & 98.7 \\
\hline $\begin{array}{l}\text { Clear about the steps of } \\
\text { EBP. }\end{array}$ & .0 & 43.6 & 17.9 & 30.8 & 7.7 & .0 & .0 & 3.8 & 53.8 & 42.3 & .0 & .0 & .0 & 25.6 & 74.4 \\
\hline $\begin{array}{l}\text { Sure, that I can implement } \\
\text { EBP. }\end{array}$ & .0 & 29.5 & 25.6 & 24.4 & 20.5 & .0 & .0 & 1.3 & 50.0 & 48.7 & .0 & .0 & .0 & 30.8 & 69.2 \\
\hline $\begin{array}{l}\text { Critically appraising } \\
\text { evidence is an important } \\
\text { step in the EBP process. }\end{array}$ & 1.3 & 19.2 & 12.8 & 35.9 & 30.8 & .0 & .0 & 1.3 & 44.9 & 53.8 & .0 & .0 & .0 & 20.5 & 79.5 \\
\hline $\begin{array}{l}\text { Evidence-based guidelines } \\
\text { can improve clinical care. }\end{array}$ & .0 & 19.2 & 3.8 & 37.2 & 39.7 & .0 & .0 & 2.6 & 34.6 & 62.8 & .0 & .0 & .0 & 16.7 & 83.3 \\
\hline $\begin{array}{l}\text { Can search for the best } \\
\text { evidence to answer clinical } \\
\text { questions in a time efficient } \\
\text { way. }\end{array}$ & .0 & 39.7 & 15.4 & 26.9 & 17.9 & .0 & 1.3 & 2.6 & 48.7 & 47.4 & .0 & .0 & 1.3 & 25.6 & 73.1 \\
\hline $\begin{array}{l}\text { Can overcome barriers in } \\
\text { implementing EBP. }\end{array}$ & 1.3 & 26.9 & 48.7 & 20.5 & 2.6 & .0 & .0 & 7.7 & 48.7 & 43.6 & .0 & .0 & .0 & 21.8 & 78.2 \\
\hline $\begin{array}{l}\text { Can implement EBP in a } \\
\text { time efficient way. }\end{array}$ & 1.3 & 14.1 & 61.5 & 16.7 & 6.4 & .0 & .0 & 9.0 & 48.7 & 42.3 & .0 & .0 & 1.3 & 30.8 & 67.9 \\
\hline $\begin{array}{l}\text { Implementing EBP will } \\
\text { improve the care that I } \\
\text { deliver to my patients. }\end{array}$ & .0 & 19.2 & 24.4 & 28.2 & 28.2 & .0 & .0 & 1.3 & 33.3 & 65.4 & .0 & .0 & .0 & 24.4 & 75.6 \\
\hline $\begin{array}{l}\text { Sure about how to measure } \\
\text { the outcomes of clinical } \\
\text { care. }\end{array}$ & .0 & 24.4 & 42.3 & 28.2 & 5.1 & .0 & .0 & 9.0 & 42.3 & 48.7 & .0 & .0 & .0 & 29.5 & 70.5 \\
\hline EBP takes too much time. & 5.1 & 19.2 & 30.8 & 37.2 & 7.7 & 43.6 & 39.7 & 7.7 & 7.7 & 1.3 & 70.5 & 28.2 & .0 & 1.3 & .0 \\
\hline $\begin{array}{llr}\text { Can access the best } \\
\text { resources in order to } \\
\text { implement EBP. }\end{array}$ & .0 & 30.8 & 43.6 & 21.8 & 3.8 & .0 & .0 & 5.1 & 56.4 & 38.5 & .0 & .0 & 2.6 & 24.4 & 73.1 \\
\hline EBP is difficult. & 6.4 & 37.2 & 19.2 & 33.3 & 3.8 & 55.1 & 35.9 & 6.4 & 1.3 & 1.3 & 74.4 & 25.6 & .0 & .0 & .0 \\
\hline $\begin{array}{l}\text { Know how to implement } \\
\text { EBP sufficiently enough to } \\
\text { make practice changes. }\end{array}$ & .0 & 47.4 & 23.1 & 25.6 & 3.8 & .0 & .0 & 9.0 & 46.2 & 44.9 & .0 & .0 & .0 & 24.4 & 75.6 \\
\hline $\begin{array}{l}\text { Confident about my ability } \\
\text { to implement EBP where I } \\
\text { work. }\end{array}$ & .0 & 29.5 & 23.1 & 41.0 & 6.4 & .0 & .0 & 5.1 & 48.7 & 46.2 & .0 & .0 & .0 & 26.9 & 73.1 \\
\hline $\begin{array}{l}\text { The care that I deliver is } \\
\text { evidence-based. }\end{array}$ & 1.3 & 35.9 & 19.2 & 38.5 & 5.1 & .0 & .0 & 3.8 & 42.3 & 53.8 & .0 & .0 & .0 & 17.9 & 82.1 \\
\hline
\end{tabular}

$\mathrm{SD}=$ Strongly Disagree, $\mathrm{D}=$ Disagree, $\mathrm{N}=$ Neutral, $\mathrm{A}=$ Agree, $\mathrm{SA}=$ Strongly Agree

Table (2): Illustrates that, $5.1 \%$ of clinical instructors strongly agreed they care delivered was evidence based increased to $53.8 \%$ of them post program then to $82.1 \%$ of them care delivered was evidence based in the follow-up program, moreover, $39.7 \%$ of clinical instructors' strongly agreed evidence-based guidelines can improve their clinical care increased to $62.8 \%$ of them post program then to $83.3 \%$ of them in follow-up program. Also, $29.5 \%$ of clinical instructors strongly agreed with EBP results in the best clinical care for patients increased to $66.7 \%$ of them post program then to $98.7 \%$ of them in follow-up program

Table (3): Means scores of clinical instructors' evidence-based practice beliefs in pre, post and follow-up program ( $\mathrm{n}=78)$.

\begin{tabular}{|c|c|c|c|c|c|}
\hline \multirow[t]{2}{*}{ Items } & Pre & Post & Follow up & \multirow[t]{2}{*}{ F } & \multirow[t]{2}{*}{$\mathrm{P}$ - value } \\
\hline & Mean \pm SD & Mean \pm SD & Mean \pm SD & & \\
\hline EBP results in the best clinical care for patients. & $4.0 \pm .875$ & $4.7 \pm .505$ & $5.1 \pm .113$ & 58.664 & $.000 * *$ \\
\hline Clear about the steps of EBP. & $3.0 \pm 1.032$ & $4.4 \pm .563$ & $4.7 \pm .439$ & 121.995 & $.000 * *$ \\
\hline Sure that I can implement EBP. & $3.4 \pm 1.116$ & $4.5 \pm .528$ & $4.7 \pm .465$ & 68.779 & $.000 * *$ \\
\hline $\begin{array}{l}\text { Critically appraising evidence is an important } \\
\text { step in the EBP process. }\end{array}$ & $3.8 \pm 1.101$ & $4.5 \pm .528$ & $4.8 \pm .406$ & 39.483 & $.000 * *$ \\
\hline $\begin{array}{l}\text { Evidence-based guidelines can improve clinical } \\
\text { care. }\end{array}$ & $4.0 \pm 1.05$ & $4.6 \pm .543$ & $4.8 \pm .375$ & 27.936 & $.000 * *$ \\
\hline $\begin{array}{l}\text { Can search for the best evidence to answer } \\
\text { clinical questions in a time efficient way. }\end{array}$ & $3.2 \pm 1.161$ & $4.4 \pm .614$ & $4.7 \pm .480$ & 74.144 & $.000 * *$ \\
\hline Can overcome barriers in implementing EBP. & $3.0 \pm .797$ & $4.4 \pm .624$ & $4.8 \pm .416$ & 177.520 & $.000 * *$ \\
\hline Can implement EBP in a time efficient way. & $3.1 \pm .779$ & $4.3 \pm .638$ & $4.7 \pm .501$ & 121.197 & $.000 * *$ \\
\hline $\begin{array}{l}\text { Implementing EBP will improve the care that I } \\
\text { deliver to my patients. }\end{array}$ & $3.7 \pm 1.091$ & $4.6 \pm .509$ & $4.8 \pm .432$ & 52.527 & $.000 * *$ \\
\hline $\begin{array}{l}\text { Sure about how to measure the outcomes of } \\
\text { clinical care. }\end{array}$ & $3.1 \pm .849$ & $4.4 \pm .651$ & $4.7 \pm .459$ & 118.561 & $.000 * *$ \\
\hline EBP takes too much time. & $2.8 \pm 1.018$ & $4.2 \pm .959$ & $4.7 \pm .546$ & 101.414 & $.000 * *$ \\
\hline Can access the best resources in order to & $3.0 \pm .829$ & $4.3 \pm .574$ & $4.7 \pm .512$ & 149.382 & $.000 * *$ \\
\hline
\end{tabular}


Minia Scientific Nursing Journal (Print) (ISSN 2537-012X) Vol. (7) No. (1) June 2020

\begin{tabular}{|c|c|c|c|c|c|}
\hline \multirow[t]{2}{*}{ Items } & Pre & Post & Follow up & \multirow[t]{2}{*}{$\mathrm{F}$} & \multirow[t]{2}{*}{$P$ - value } \\
\hline & Mean \pm SD & Mean \pm SD & Mean \pm SD & & \\
\hline \multicolumn{6}{|l|}{ implement EBP. } \\
\hline EBP is difficult. & $3.1 \pm 1.059$ & $4.4 \pm .782$ & $4.7 \pm .439$ & 93.477 & $.000 * *$ \\
\hline $\begin{array}{l}\text { Know how to implement EBP sufficiently enough } \\
\text { to make practice changes. }\end{array}$ & $2.9 \pm .935$ & $4.4 \pm .644$ & $4.8 \pm .432$ & 158.590 & $.000 * *$ \\
\hline $\begin{array}{l}\text { Confident about my ability to implement EBP } \\
\text { where I work. }\end{array}$ & $3.2 \pm .955$ & $4.4 \pm .591$ & $4.7 \pm .446$ & 98.034 & $.000 * *$ \\
\hline The care that I deliver is evidence-based. & $3.1 \pm 1.001$ & $4.5 \pm .575$ & $4.8 \pm .386$ & 131.700 & $.000 * *$ \\
\hline
\end{tabular}

$* *=$ Highly statistical significance difference $P$ - value at .01

Table (3): presents that mean scores of clinical instructors' evidence-based practice beliefs was increased post program than pre-program implementation and follow up session was increased than pre and post program with highly statistically significance differences in all statement.

Table (4): Relations between clinical instructors' evidence-based practice implementation in pre, post and follow-up program $(\mathbf{n}=78)$.

In the past 8 weeks, I have:

\begin{tabular}{|c|c|c|c|c|c|c|c|c|c|c|c|c|c|c|}
\hline \multicolumn{5}{|c|}{ Pre } & \multicolumn{5}{|c|}{ Post } & \multicolumn{5}{|c|}{ Follow up } \\
\hline $\mathbf{0}$ & $1-3$ & $\begin{array}{c}4- \\
5\end{array}$ & $\begin{array}{c}\text { 6- } \\
7\end{array}$ & $>8$ & 0 & $1-3$ & 4-5 & 6-7 & $>8$ & $\mathbf{0}$ & $1-3$ & 4-5 & 6-7 & $>8$ \\
\hline$\%$ & $\%$ & $\%$ & $\%$ & $\%$ & $\%$ & $\%$ & $\%$ & $\%$ & $\%$ & $\%$ & $\%$ & $\%$ & $\%$ & $\%$ \\
\hline 59.0 & 34.6 & 1.3 & 3.8 & 1.3 & 2.6 & 78.2 & 14.1 & 3.8 & 1.3 & .0 & 51.3 & 43.6 & 3.8 & 1.3 \\
\hline 60.3 & 26.9 & 6.4 & 5.1 & 1.3 & 5.1 & 74.4 & 2.8 & 7.7 & .0 & .0 & 57.7 & 34.6 & 7.7 & .0 \\
\hline 66.7 & 23.1 & 5.1 & 2.6 & 2.6 & 2.6 & 73.1 & 15 & 7.7 & 1.3 & .0 & 56.4 & 34.6 & 7.7 & 1.3 \\
\hline 62.8 & 26.9 & 5.1 & 1.3 & 3.8 & 2.6 & 66.7 & 19.2 & 9.0 & 2.6 & .0 & 56.4 & 32.1 & 7.7 & 3.8 \\
\hline 57.7 & 25.6 & 6.4 & 6.4 & 3.8 & 1.3 & 69.2 & 14.1 & 5.1 & 10.3 & .0 & 60.3 & 23.1 & 6.4 & 10.3 \\
\hline 62.8 & 29.5 & 2.6 & 2.6 & 2.6 & 2.6 & 71.8 & 14.1 & 7.7 & 3.8 & .0 & 52.6 & 35.9 & 7.7 & 3.8 \\
\hline 64.1 & 5.6 & 6. & 2.6 & 1.3 & 2.6 & 75.6 & & 3.8 & 5. & & 60.3 & 30.8 & 3.8 & 5.1 \\
\hline 65.4 & 26.9 & 5 & 2.6 & .0 & 2.6 & 71.8 & 17.9 & 5.1 & 2.6 & & 50.0 & 41.0 & 6.4 & 2.6 \\
\hline 75.6 & 17.9 & 1.3 & 3.8 & 1.3 & 2.6 & 73.1 & 15.4 & 6.4 & 2.6 & .0 & 59.0 & 32.1 & 6.4 & 2.6 \\
\hline 66.7 & 26.9 & 2.6 & 3.8 & .0 & .0 & 70.5 & 23.1 & 3.8 & 2.6 & .0 & 56.4 & 35.9 & 5.1 & 2.6 \\
\hline 64.1 & 23.1 & 6. & 5.1 & 1.3 & .0 & 61.5 & 24.4 & 11.5 & 2. &. & 50.0 & 35.9 & 11.5 & 2.6 \\
\hline 65.4 & 21.8 & 7.7 & .0 & 5.1 & .0 & 52.6 & 38. & 3.8 & 5.1 & .0 & 48.7 & 41.0 & 5.1 & 5.1 \\
\hline 76.9 & 11.5 & 9.0 & .0 & 2.6 & 1.3 & 56.4 & 37.2 & 2.6 & 2.6 & .0 & 43.6 & 51.3 & 2.6 & 2.6 \\
\hline 64.1 & 30.8 & 1.3 & 2.6 & 1.3 & 1.3 & 60.3 & 30.8 & 6.4 & 1.3 & .0 & 48.7 & 43.6 & 6.4 & 1.3 \\
\hline 69.2 & 23.1 & 3.8 & 2.6 & 1.3 & 1.3 & 66.7 & 25.6 & 3.8 & 2.6 & .0 & 57.7 & 35.9 & 3.8 & 2.6 \\
\hline 74.4 & 19.2 & 1.3 & 3.8 & 1.3 & 1.3 & 73.1 & 15. & 7.7 & 2.6 & .0 & 59.0 & 30.8 & 7.7 & 2.6 \\
\hline 70.5 & 17.9 & 3.8 & 5.1 & 2.6 & 1.3 & 70.5 & 14 & 10.3 & 3.8 & .0 & 56.4 & 28.2 & 10.3 & 5.1 \\
\hline 71.8 & 50.5 & 2.6 & 1.3 & 3.8 & .0 & 67.9 & 23.1 & 5.1 & 3.8 & .0 & 60.3 & 29.5 & 6.4 & 3.8 \\
\hline
\end{tabular}

1. Used evidence to change their clinical

Practice.

2. Critically appraised evidence from a research study.

3. Generated a PICO question about their clinical practice.

4. Informally discussed evidence from a research study with a colleague.

5. Collected data on a patient problem.

6. Shared evidence from a study/ies in the form of a report

or presentation to $>2$ colleagues.

7. Evaluated the outcomes of a practice change.

8. Shared an EBP guideline with a colleague.

9. Shared evidence from a research study with a patient/family member.

10. Shared evidenced from a research study with a multidisciplinary team member

11. Read and critically appraised a clinical research study 12. Accessed the Cochrane database of systematic reviews

13. Accessed the National Guidelines Clearinghouse.

14. Used an EBP guideline or systematic review to change clinical practice where I work.

15. Evaluated a care initiative by collecting patient outcome data.

16. Shared the outcome data with colleagues.

17. Changed practice based on patient outcome data.

18. Promoted the use of EBP to my colleagues.

Table (4): shows that, more than half of clinical instructors don't implemented evidence-based practice in their clinical preprogram decreased to minority of them post program then none of them in follow-up the program.

Table (5): The means scores of clinical instructors' evidence-based practice implementation in pre, post and follow-up program $(n=78)$.

\begin{tabular}{|c|c|c|c|c|c|}
\hline \multirow[t]{2}{*}{ Items } & Pre & Post & Follow up & \multirow[t]{2}{*}{$\mathrm{F}$} & \multirow[t]{2}{*}{$\mathrm{P}-$ value } \\
\hline & Mean \pm SD & Mean \pm SD & $\mathrm{n} \pm \mathrm{SD}$ & & \\
\hline $\begin{array}{l}\text { 1. Used evidence to change my clinical } \\
\text { Practice. }\end{array}$ & $1.5 \pm .817$ & $2.2 \pm .622$ & $2.6 \pm .638$ & 42.908 & $.000 * *$ \\
\hline 2. Critically appraised evidence from a research study. & $1.6 \pm .917$ & $2.2 \pm .663$ & $2.5 \pm .639$ & 29.389 & $.000 * *$ \\
\hline 3. Generated a PICO question about my clinical practice. & $1.5 \pm .908$ & $2.3 \pm .712$ & $2.5 \pm .697$ & 37.614 & $.000 * *$ \\
\hline 4. Informally discussed evidence from a research study with a colleague. & $1.6 \pm .948$ & $2.4 \pm .798$ & $2.6 \pm .797$ & 32.666 & $.000 * *$ \\
\hline 5. Collected data on a patient problem. & $1.7 \pm 1.089$ & $2.5 \pm 1.002$ & $2.7 \pm .989$ & 19.006 & $.000 * *$ \\
\hline 6. Shared evidence from a study/ies in the form of a report or presentation to $>2$ colleagues. & $1.5 \pm .879$ & $2.4 \pm .825$ & $2.6 \pm .791$ & 37.748 & $.000 * *$ \\
\hline 7. Evaluated the outcomes of a practice change. & $1.5 \pm .833$ & $2.3 \pm .817$ & $2.5 \pm .800$ & 34.416 & $.000 * *$ \\
\hline 8. Shared an EBP guideline with a colleague. & $1.4 \pm .714$ & $2.3 \pm .733$ & $2.6 \pm .725$ & 55.135 & $.000 * *$ \\
\hline 9. Shared evidence from a research study with a patient/family member. & $1.4 \pm .808$ & $2.3 \pm .750$ & $2.5 \pm .733$ & 51.004 & $.000 * *$ \\
\hline 10. Shared evidenced from a research study with a multidisciplinary team member & $1.4 \pm .731$ & $2.4 \pm .688$ & $2.5 \pm .715$ & 54.899 & $.000 * *$ \\
\hline 11. Read and critically appraised a clinical research study & $1.6 \pm .920$ & $2.6 \pm .800$ & $2.7 \pm .784$ & 40.895 & $.000 * *$ \\
\hline 12. Accessed the Cochrane database of systematic reviews & $1.6 \pm .1 .013$ & $2.6 \pm .793$ & $2.7 \pm .800$ & 38.525 & $.000 * *$ \\
\hline 13. Accessed the National Guidelines Clearinghouse. & $1.4 \pm . .858$ & $2.5 \pm . .698$ & $2.6 \pm . .664$ & 64.641 & $.000 * *$ \\
\hline 14. Used an EBP guideline or systematic review to change clinical practice where I work. & $1.5 \pm . .768$ & $2.5 \pm . .697$ & $2.6 \pm . .671$ & 59.366 & $.000 * *$ \\
\hline 15. Evaluated a care initiative by collecting patient outcome data. & $1.4 \pm . .799$ & $2.4 \pm . .708$ & $2.5 \pm . .698$ & 50.254 & $.000 * *$ \\
\hline 16. Shared the outcome data with colleagues. & $1.4 \pm . .809$ & $2.4 \pm . .758$ & $2.5 \pm . .751$ & 50.759 & $.000 * *$ \\
\hline 17. Changed practice based on patient outcome data. & $1.5 \pm . .977$ & $2.4 \pm . .847$ & $2.6 \pm . .868$ & 35.151 & $.000 * *$ \\
\hline 18. Promoted the use of EBP to my colleagues. & $1.4 \pm . .920$ & $2.4 \pm . .767$ & $2.5 \pm . .784$ & 41.737 & $.000 * *$ \\
\hline
\end{tabular}

$P$ a g e | 12

Essam A., et al 
**= Highly statistical significance difference $P$ - value at .01

Table (5): presents that, mean scores of clinical instructors' evidence-based practice implementation was increased post program than pre-program and follow up session was increased than pre and post program with highly statistically significance differences in all statement

Table (6): Relations between clinical instructors' total evidence-based practice beliefs and implementation in pre, post and follow-up program $(n=78)$.

\begin{tabular}{|c|c|c|c|c|c|c|}
\hline \multirow[t]{2}{*}{ Items } & \multicolumn{2}{|c|}{ Pre } & \multicolumn{2}{|c|}{ Post } & \multicolumn{2}{|c|}{ Follow up } \\
\hline & NO. & $\%$ & NO. & $\%$ & NO. & $\%$ \\
\hline \multicolumn{7}{|l|}{ Evidence-Based Practice Beliefs } \\
\hline $1-3$ & 62 & 79.5 & 4 & 5.1 & 0 & .0 \\
\hline $6-7$ & 2 & 2.6 & 7 & 9.0 & 8 & 10.3 \\
\hline 8 & 2 & 2.6 & 6 & 3.8 & 3 & 3.8 \\
\hline \multicolumn{7}{|l|}{ Evidence-Based Practice Implementation } \\
\hline No full commitment & 53 & 67.9 & 6 & 7.7 & 0 & .0 \\
\hline $\begin{array}{l}\text { Greater with knowledge confidence in and belief in their } \\
\text { ability to implement EBP }\end{array}$ & 6 & 7.7 & 72 & 92.3 & 78 & 100.0 \\
\hline
\end{tabular}

Table (6): presents that, $15.4 \%$ of clinical instructors implement $4-5$ times pre-implement EBP program vs $82.1 \%$ and $85.9 \%$ of them post and follow-up program while $7.7 \%$ of them had greater with knowledge confidence in and belief in their ability to implement EBP preprogram vs $92.3 \%$ and $100.0 \%$ of them post and follow-up program.

Table (7): Relations between clinical instructors' total evidence-based practice beliefs and implementation in pre, post and follow-up program $(n=78)$.

\begin{tabular}{|l|c|c|c|c|c|}
\hline \multicolumn{1}{|c|}{ Items } & Pre & Post & Follow up & \multirow{2}{*}{ F } & $P-$ value \\
\cline { 2 - 5 } & Mean \pm SD & Mean \pm SD & Mean \pm SD & & \\
\hline Evidence-Based Practice Beliefs & $52.3 \pm 10.748$ & $71.0 \pm 5.087$ & $76.1 \pm 2.532$ & 249.399 & $.0001^{* *}$ \\
\hline Evidence-Based Practice Implementation & $27.0 \pm 3.307$ & $43.3 \pm 10.712$ & $46.5 \pm 9.9$ & 65.274 & $.0001^{* *}$ \\
\hline
\end{tabular}

$* *=$ highly statistical significance difference $P$ - value at .01

Table (7): shows that, total mean scores of clinical instructors' evidence-based practice implementation was increased post program than pre-program and follow up session was increased than pre and post program and total mean scores of clinical instructors' evidence-based practice beliefs was increased post program than pre-program and follow up session was increased than pre and post program with highly statistically significance differences which $P$ - value .0001 respectively

Table (8): Correlation matrix between age of clinical instructors, their years of experience, evidence based practice beliefs, and evidence based practice implementation in pre, post and follow-up of program $(n=78)$

\begin{tabular}{|c|c|c|c|c|c|c|c|c|c|c|c|c|}
\hline \multirow[b]{2}{*}{ Items } & \multicolumn{4}{|c|}{ Pre } & \multicolumn{4}{|c|}{ Post } & \multicolumn{4}{|c|}{ Follow up } \\
\hline & Age & $\begin{array}{l}\text { Years of } \\
\text { experience }\end{array}$ & EBPB & EBPI & Age & $\begin{array}{l}\text { Years of } \\
\text { experience }\end{array}$ & EBPB & EBPI & Age & $\begin{array}{l}\text { Years of } \\
\text { experience }\end{array}$ & EBPB & EBPI \\
\hline \multicolumn{13}{|l|}{ Age } \\
\hline \multicolumn{13}{|l|}{$\mathrm{R}$} \\
\hline \multicolumn{13}{|l|}{$P$ - value } \\
\hline \multicolumn{13}{|l|}{$\begin{array}{l}\text { Years of } \\
\text { experience }\end{array}$} \\
\hline $\mathrm{R}$ & .934 & & & & .934 & & & & .934 & & & \\
\hline $\mathrm{P}$ - value & $.000 * *$ & & & & $.000^{* *}$ & & & & $.000^{* *}$ & & & \\
\hline \multicolumn{13}{|l|}{ EBPB } \\
\hline $\mathrm{R}$ & .138 & .123 & & & .202 & .193 & & & .093 & .107 & & \\
\hline $\mathrm{P}$ - value & .228 & .284 & & & .077 & .091 & & & .418 & .352 & & \\
\hline \multicolumn{13}{|l|}{ EBPI } \\
\hline $\mathrm{R}$ & -.066 & .010 & .484 & & .077 & .155 & .100 & & .059 & .124 & .010 & \\
\hline $\mathrm{P}$ - value & .566 & .931 & $.000 * *$ & & .501 & .176 & .382 & & .605 & .280 & .934 & \\
\hline
\end{tabular}

**Correlation is significant at the .01 level

Table (8): represents that, there were positive strong association between age of clinical instructors and their years of experience in pre, post and in follow-up of program and there was positive fair association between evidence based practice beliefs of clinical instructors pre the program with evidence based practice implementation which $\mathrm{r}=.484$ and $P-$ value .000

\section{Discussion}

Regarding to the demographic characteristics of the clinical instructors, revealed that $50.0 \%$ of clinical instructors aged between $29-34$ years with mean aged $30.4 \pm 3.9$ years, $84.6 \%$ of them were female, $74.4 \%$ of them married and $69.2 \%$ of them had master degree. Regarding years of experience $39.7 \%$ of clinical instructors their experience ranged between $1-5$ years and $33.3 \%$ of sample was in medical surgical department. These results were supported by the study to assess Nursing Educators' Knowledge, Skills in Evidence-Based Practice and their Critical Thinking Skills by Hussein and Hussein , (2014) (7) who showed that MedicalSurgical Nursing specialty represented the highest capacity of nursing educators, $97.9 \%$ of the nursing educators were females. 
Regarding to beliefs toward evidence based practice the study showed that $5.1 \%$ of clinical instructors strongly agreed they care delivered was evidence based increased to $53.8 \%$ of them post program then to $82.1 \%$ of them care delivered was evidence based in the follow-up program, moreover, $39.7 \%$ of clinical instructors' strongly agreed evidence-based guidelines can improve their clinical care increased to $62.8 \%$ of them post program then to $83.3 \%$ of them in follow-up program. Also, $29.5 \%$ of clinical instructors strongly agreed with EBP results in the best clinical care for patients increased to $66.7 \%$ of them post program then to $98.7 \%$ of them in follow-up program. This finding may supported by the finding of the study conducted by Snibsøer, Espehaug,Ciliska \& Nortvedt (2017), (11 ) who indicated a statistically significant positive change in scores reported before and one year after the postgraduate program. The largest percentage of respondents with improved scores was for the items 'I am clear about the steps of EBP' (88\%), 'I know how to implement EBP sufficiently enough to make practice changes' (68\%) and 'I am confident about my ability to implement EBP where I work' (67\%). More than $80 \%$ of the participants answered 'agree' and 'strongly agree' before the program started for other items.

Regarding to evidence based practice implementation, the study showed more than half of clinical instructors don't implemented evidence-based practice in their clinical preprogram decreased to minority of them post program then none of them in follow-up the program. This finding may supported by the finding of the study conducted by Snibsøer, Espehaug,Ciliska \& Nortvedt (2017)(11). Result revealed a statistically significant change in implementation score after the postgraduate program. There are studies reporting larger increase in mean EBP implementation sores (12-13-14).

In the present study, the finding revealed that total mean scores of clinical instructors' evidence-based practice implementation was increased post program than pre-program and follow up session was increased than pre and post program and total mean scores of clinical instructors' evidence-based practice beliefs was increased post program than pre-program and follow up session was increased than pre and post program with highly statistically significance differences which $\mathrm{P}$ - value .0001 respectively. This finding may supported by the finding of the study conducted by Eldeeb \& Bakeer (2016), (15) who indicated that there were statistical significant improvements in the three EBP domains(attitude, skills and knowledge) in the post test in comparison to pretest.

Regarding to the relation between beliefs and implementation to evidence based practice, the study showed that there were positive strong association between age of clinical instructors and their years of experience in pre, post and in follow-up of program and there was positive fair association between evidence based practice beliefs of clinical instructors pre the program with evidence based practice implementation which $\mathrm{r}=.484$ and $\mathrm{P}-$ value .000 . This finding was consistent with the findings of earlier authors as (16-17-18-19) who associated levels of EBP implementation with nurses' educational levels, professional roles and years of experience. This finding was consistent with those reported in other studies (18-19-20). This finding was consistent with the study done by (Pereira, Pellaux\& Verloo, 2018) (21). A positive correlation was observed between the EBP Beliefs Scale and the EBP Implementation Scale $(q=.764, p<.001)$.

\section{Conclusion}

- Findings of the research demonstrated that education and years of experience can affect the clinical instructor's belief and implementation to use EBP.

- Clinical instructors' evidence-based practice beliefs and implementation were increased post program than preprogram and follow up sessions.

\section{Recommendations}

Based on the findings of the current study the following recommendations suggested:

- $\quad$ EBP should be incorporate across undergraduate and postgraduate curricula at Faculty of Nursing.

- Repetition of the educational program in other nursing Faculties needs to be done on the use and implementation of EBP to improve faculty attitude toward EBP.

- Encourage hospital's administrators to provide a work environment that identifies research evidence that will give nurses and clinical instructors opportunities for search evidence, ask questions, evaluating each evidence for possibility of its application.

- The library of the faculty should have new issues of nursing journals to help clinical instructors in searching new evidences and follow up updates in nursing.

\section{References}

1. Alhadid, L. A., Abu Hasheesh, M., \& Almomani, M.( 2011): "Validating a tool that explores influencing the adoption of principles of evidence-based practice".Journal of Nursing Education:, 50, 681-687. doi:10.3928/01484834- 20110930-03

2. Baird, L. M. G., \& Miller, T. (2015): Factors influencing evidence based practice for community nurses. British Journal of Community Nursing, 20, 233-242. https://doi.org/10.12968/bjen.2015.20.5. 233

3. Cobus-Kuo, L., \& Waller, J. (2016): Teaching information literacy and evidence-based practice in an undergraduate speech-language pathology program: A student reflection. Contemporary Issues in Communication Science and Disorders, 43, 35-49. doi: 1092.5171/16/4301-0035

4. Cruz, J., Colet, P., Alquwez, N., Alqubeilat, H., Bashtawi, M. A., Ahmed, E. A., \& Cruz, C. (2016): Evidence-Based Practice Beliefs and Implementation among the Nursing Bridge Program Students of a Saudi University. International Journal of Health Sciences, 10(3). Retrieved from https://ijhs.org.sa/index.php/journal/article/view/1382

5. Eldeeb, G. A., \& Bakeer, H. M. (2016): Effect of an Educational Program on Nursing Interns' Evidence Based Practice Attitude, Knowledge and Skills. OSR Journal of Nursing and Health Science (IOSR-JNHS), 5(3), 12-18. doi:10.9790/1959-0503011218

6. Heikkila, J., Hopia, H., Hasselberg, J., Tiittanen, H. \& Biaghorzina, Z., (2017): 'A cross sectional study of nurses' and nurse educators' perceptions of evidence-based practice in Kazakhstan', Annals of Nursing Research and Practice 2(1), 1016.

7. Hussein A.H.M. \& Hussein R.G., 2014, 'Nursing educators' knowledge, skills in evidence-based practice and their critical thinking skills. Self-report study', Journal of Education and Practice 5(27), 860-894.

8. Kinnunen, U. M., Rajalahti, E., Cummings, E., \& Borycki, E. M. (2017): Curricula challenges and informatics competencies for nurse educators. Forecasting Informatics Competencies for Nurses in the Future of Connected Health, 41, 4148. doi:10.3233/978-1-61499-738-2-41

9. Levin, RF, Fineout-Overholt, E, Melnyk, BM (2011): Fostering evidence-based practice to improve nurse and cost outcomes in 
a community health setting: a pilot test of the advancing research and clinical practice through close collaboration model. Nurs Adm Q; 35: 21-33.

10. Majid, S., Foo, S., Luyt, B., Zhang, X., Theng, Y.-L., Chang, Y.-K., \& Mokhtar, I. A. (2011): Adopting evidence-based practice in clinical decision making: Nurses' perceptions, knowledge, and barriers. Journal of the Medical Library Association, 99, 229-236. https://doi.org/10.3163/ 15365050.99.3.010

11. Mehrdad, N., Joolaee, S., Joulaee, A., Bahrani, N.(2012): Nursing faculties' knowledge and attitude on evidence-based practice. Iranian Journal of Nursing and Midwifery Research, 17(7), 506.

12. Melnyk BM, Fineout-Overholt E, Mays MZ. (2008). The evidence-based practice beliefs and implementation scales: psychometric properties of two new instruments. Worldviews Evidence-based Nursing,5(4), 208-16. doi: 10.1111/j.17416787.2008.00126.x

13. Melnyk, B. M., Gallagher-Ford, L., Long, L. E., \& FineoutOverholt, E. (2014): The establishment of evidence-based practice competencies for practicing registered nurses and advanced practice nurses in real-world clinical settings: Proficiencies to improve healthcare quality, reliability, patient outcomes, and costs. Worldviews on Evidence-Based Nursing, 11(1), 5-15.

14. Melnyk, BM, Bullock, T, McGrath, J (2010): Translating the evidence-based NICU COPE Program for parents of premature infants into clinical practice: impact on nurses' evidence-based practice and lessons learned. J Perinat Neonatal Nurs; 24: 74 80.
15. Pereira F, Pellaux V, Verloo H. (2018): Beliefs and implementation of evidence-based practice among community health nurses: A cross-sectional descriptive study. J Clin Nurs ;27:2052-2061. https://doi.org/10.1111/jocn.14348

16. Sewell, J. (2019): Informatics and nursing: Opportunities and challenges (6th ed.).Philadelphia, PA: Wolters Kluwer.

17. Snibsøer, A. K., Espehaug, B., Ciliska, D., \& Nortvedt, M. W. (2017): Changes in evidence-based practice beliefs and implementation after a postgraduate educational program: A before-and-after study over one year. Socius, 37(3). https://doi.org/10.1177/2378023117710578

18. Stokke, K., Olsen, N. R., Espehaug, B., \& Nortvedt, M. W. (2014): Evidence based practice beliefs and implementation among nurses: A cross-sectional study. BMC Nursing, 13, 8. https://doi.org/10.1186/ 1472-6955-13-8

19. Thorsteinsson, H. S. (2013). Icelandic nurses' beliefs, skills, and resources associated with evidence-based practice and related factors: A national survey. Worldviews on EvidenceBased Nursing, 10, 116-126. https://doi.org/10.1111/j.17416787.2012.00260.x

20. Underhill, M., Roper, K., Siefert, M. L., Boucher, J., \& Berry, D. (2015). Evidence-based practice beliefs and implementation before and after an initiative to promote evidence-based nursing in an ambulatory oncology setting. Worldviews on Evidence-Based Nursing, 12, 70-78. https://doi.org/10.1111/wvn. 12080

21. Wallen, GR, Mitchell, SA, Melnyk, B. (2010): Implementing evidence-based practice: effectiveness of a structured multifaceted mentorship programme. J Adv Nurs; 66: 27612771. 